\title{
Differences and Commonalities of National Field Epidemiology Training Programmes in Europe
}

\author{
G Krause (KrauseG@rki.de) ${ }^{1}$, P Aavitsland², K Alpers ${ }^{1}$, A Barrasa $^{3}$, V Bremer $^{4}$, B Helynck ${ }^{5}$, A Perra $^{6}$ \\ 1. Robert Koch Institute, Berlin, Germany \\ 2. The Norwegian Institute of Public Health, Olso, Norway \\ 3. Instituto de Salud Carlos III, Madrid, Spain \\ 4. European Centre for Disease Prevention and Control, Stockholm, Sweden \\ 5. Institut de Veille Sanitaire, Paris, France \\ 6. Istituto Superiore di Sanità, Rome, Italy
}

This article was published on 29 October 2009.

Citation style for this article: Krause G, Aavitsland P, Alpers K, Barrasa A, Bremer V, Helynck B, Perra A. Differences and Commonalities of National Field Epidemiology

Training Programmes in Europe. Euro Surveill. 2009;14(43):pij=19378. Available online: http://www.eurosurveillance.org/ViewArticle.aspx?ArticleId=19378

From 1994 to 2009, national field epidemiology training programmes (FETP) have been installed in Spain, Germany, Italy, France and Norway. During their two year duration, different components of the FETP are devised as follows: 63-79 weeks are spent on projects in hosting institutes, 2-26 weeks in outside projects, 9-30 weeks in courses and modules, and 1-2 weeks in scientific conferences. A considerable proportion of the Spanish FETP has is provided conventional 'class room training'. The content of the modules is very similar for all programmes. Except from the Italian programme, all focus on infectious disease epidemiology. The German and Norwegian programmes are so called EPIET-associated programmesas their participants are integrated in the modules and the supervision offered by EPIET, but salaries, facilitators, and training sites are provided by the national programme. These EPIET-associated programmes require strong communications skills in English. Alumni of all five FETP are generally working within the public health work force in their respective countries or at international level, many of them in leading functions. Although three new FETP have been installed since the last published 'Euroroundup' in Eurosurveillance on European FETP in 2001, the progress with respect to the establishment of national FETP or EPIET-associated programmes has been slow. Member States should be aware of how much support EPIET can offer for the establishment of national FETP or EPIET-associated programmes. However, they also need to be ready to provide the necessary resources, the administrative environment and long-term dedication to make field epidemiology training work.

\section{Introduction}

In March 2001, a special issue of Eurosurveillance presented reports on different field epidemiology training programmes (FETP) in Europe and the United States [1,2]. At that time, in Europe, national FETP were in place in France, Germany and Spain. These three programmes now look back on more than 10 years of experience and Norway and Italy have created additional national FETP since. This 'Euroroundup' aims to provide an overview of the existing five national FETP. It focuses on their respective history, their objectives and organisational details and discusses differences and commonalities with reference to the European Programme for Intervention Epidemiology Training (EPIET) as it is a multinational field epidemiology training programme in Europe. Furthermore, the analysis intends to provide a basis for further discussions of the strengths of FETPS for capacity building in Europe and the remaining challenges.

\section{France}

Since the late 1990s, changes occurred in the French public health arena: in 1998 the Institute of Public Health Surveillance (InVS) and its regional offices were created to reinforce the surveillance of and response to alerts and threats to public health and in 2002, in the context of bioterrorist threats, the French Field Epidemiology Training Programme PROFET (Programme de formation à l'épidémiologie de terrain) was launched. The programme was run in cooperation between the InVS and the National School of Public Health (EHESP) and built on a threeweek intervention epidemiology course (IDEA) which had been ongoing since $1984[3,4]$. PROFET was set up with the aim to build capacity for preparedness and response in the field of public health, and in the development of public health surveillance. It intended to provide qualified professionals primarily to the national institute and its regional offices.

As most FETP, PROFET is based on the principle of 'learning by doing', fellows may carry out projects in the field of communicable diseases and environmental health, but also in occupational health, chronic diseases and injuries. They are expected to publish in the French national epidemiologic bulletin or in other national or international journals, and to give an oral presentation at an epidemiologic conference. During their two year training, the fellows attend six one-week training modules with specific topics: computer tools for outbreak investigation, risk assessment in environmental health, logistic regression, sampling, scientific writing, surveillance. The training is conducted in French by InVS epidemiologists and set up specifically for the fellows. However, some modules are open for external participants as well. At the end of the training, an assessment is made of the outcomes of the fellows but no formal diploma is awarded upon completion.

PROFET targets young public health professionals who are willing to get involved in field epidemiology in the French public health system. Candidates must have a master degree in the field 
of public health, or equivalent. The programme is run jointly by two scientific coordinators from InVS and EHESP (respectively 0.7 and 0.3 fulltime equivalents [FTE]). Fellows are employed and paid by InVS with a specific trainee salary. The cost of the programme is mainly made up of salaries (90\%) and of travel costs for training and conferences (9\%). Costs directly related to the daily activities are included in the training site's budget. Since 2002, seven cohorts have been enrolled, amounting to 40 fellows (five cohorts of six fellows each and the two last cohorts of five fellows each). Trainees were mainly public health graduates (master in public health, or epidemiology), public health engineers, biostatisticians, pharmacists, public health nurses and veterinarians. Only one physician entered PROFET because medical students who want to specialise in field epidemiology generally apply for a residency at InVS during their public health medicine training. All 30 fellows of the five completed cohorts have successfully terminated the programme and all, except one, have been recruited in the public health network after this: 19 at InVS (11 at the national headquarters, 8 in regional offices) and 10 work for other public health partners in France.

After eighteen years of successful experiences with the IDEA course, the start of PROFET was intended to accompany the development and the regionalisation of the surveillance and response capacities in the French public health system. The cost of such training activities are usually seen as a challenge in setting up and maintaining programmes but an evaluation of PROFET carried out in 2008 showed that the training sites highly value the input of fellows, not only as a 'workforce' but also because of their organisational and methodological skills. The next challenge for PROFET will be to become part of the European network of training programmes. The collaboration of InVS with the European Centre for Disease Prevention and Control (ECDC) and its involvement in the European Programme for Intervention Epidemiology Training (EPIET) as well as the European focus of the EHESP are opportunities for PROFET to be addressed in the future.

\section{Germany}

In the 1990s the German Ministry of Health (MOH) initiated a number of measures to strengthen the federal capacity in the field of infectious disease epidemiology. One of these measures was the installation of a national FETP in 1996 [5]. The idea was that participants would upon completion of their training either join the Robert Koch Institute (RKI) or return to the peripheral health departments, from where most of them were initially recruited. The programme started with two participants and - due to various kinds of additional government funding - has in the meanwhile had up to six participants per cohort. In 2006 the programme was named Postgraduate Training for Applied Epidemiology (PAE).

From start, the PAE was organised as an EPIET-associated programme, which means that the PAE fellows participate in all EPIET modules and benefit from facilitation by EPIET coordinators. However, salaries for fellows, the German facilitators and coordinators within the EPIET programme and the training sites are provided by the RKI. This EPIET-associated FETP requires strong communication skills in English. In addition to the EPIET modules $\mathrm{RKI}$ is conducting a one-week introductory module and a laboratory module for PAE at the RKI laboratories (bacteriology and virology) as well as additional activities such as journal clubs and scientific seminars. In addition to the requirements for EPIET fellows $[6,11]$, PAE fellows are expected to write at least one publication in the national weekly epidemiological bulletin, one chapter in the annual national epidemiological report and are involved in the regular quality control procedures of the national surveillance system. Usually PAE fellows also enrol as duty officer in the RKI 24/7 hotline for public health emergencies.

The PAE primarily targets individuals with fairly advanced training and work experience in a medical or related discipline. Besides a university degree, eligibility criteria include knowledge in public health or epidemiological methods, at least one year programmerelated work experience and fluency in English and German. RKI closely cooperates with EPIET. The institute provides facilitators, locations and sometimes funding for some of the EPIET modules. For cohort 13/14 (2006-2009) RKI is training site for six PAE and two EPIET fellows. In addition four PAE fellows are currently being trained at the respective state public health agencies of Hesse, Lower Saxony, North Rhine-Westphalia and Baden Wuerttemberg. In 2009, two of the state agencies have also become EPIET training sites and one is now hosting an EPIET fellow.

Of the 42 fellows who entered the programme between 19962008, 36 had a medical degree, thee a university degree in veterinary medicine, one a degree in biology, one in traditional Chinese medicine and one in public health. Most participants had worked outside the public health service upon entry to the programme, seven had completed a master degree in a public health-related field before starting the training, four obtained a master degree after termination of the PAE. Most fellows (38) had applied from outside RKI but within Germany, two applicants came from a neighbouring European country, two had no European citizenship. Forty of the 42 fellows admitted have successfully completed their training, two dropped out before completion of the programme (one because of another job offer, one for personal reasons).

Retrospectively, the main challenge in setting up the programme was to reach an acknowledgement at ministerial level that such a training programme is a necessary and fruitful investment. The PAE has undergone a remarkable expansion and stabilisation in the past years [7]. To have some of the PAE fellows trained in state public health agencies is maybe one of the most important achievements given the difficulties for such collaboration in a federal setting. As a result of close collaboration between RKI and the Charité Medical University in Berlin, the cohort starting 2009, will upon successful completion of the PAE also obtain a Master of Science degree in Applied Epidemiology (MScAE).

\section{Italy}

At the end of the 1980s, after several exchanges of experiences and health professionals with the US Centers for Disease Control and Prevention (CDC), Atlanta, the Istituto Superiore di Sanità (ISS, National Institute of Health) set up an experimental training programme to train some health professionals from the different regions in order to improve the preparedness to intervene essentially on outbreaks and to carry out epidemiological surveillance of infectious diseases. In 2000, the training programme for applied epidemiology PROgramma di Formazione in Epidemioloiga Applicata (PROFEA) was created. At present, most of the curriculum focuses on prevention for chronic diseases, even if a section of the training is devoted to infectious disease surveillance and outbreak investigation. 
The curriculum contains 10 different modules followed by a field training assignment of one or two months. Each trainee has to achieve some formative objectives using exclusively data and information from his/her reality and is required to devote 1,500 hours during two years PROFEA, approximately $50 \%$ of the working time of a health professional employed by the National Health System. The training is held in Italian, even if the curriculum requires an article for a scientific journal and that all participants are invited write their article in English. In 2002, PROFEA became a post-graduate Master course, through collaboration with the 'Tor Vergata' University in Rome.

In the past mostly medical doctors, veterinarians, biologists and statisticians have applied for PROFEA directly via the university. A particular condition to be eligible for PROFEA is a letter from the region or local health administration ( $L A H)$ of the applicant in which it confirms to financially support courses, workshops and fieldworks and assures that the candidate will be able to dedicate $50 \%$ of his/her working time to the training programme. Organised by the National Centre of Epidemiology (CNESPS), of the ISS, the training programme is carried out by teachers and tutors from CNESPS. So far, secured permanent funding has come from the Italian CDC (CCM from the Ministry of Health). All participants are already employed by regions or LHA and their employers cover financial costs of courses, travels, hotel and other costs generated from training or fieldwork activities.

Since 2001, six cohorts have enrolled the programme. Fifty participants now work in public health in Italy, many of whom were promoted to posts of greater responsibility, while others are involved in national and regional committees.

At the moment, PROFEA and the CNESPS face many challenges. Italy is becoming a federal republic and the national level is only entitled to establish essential levels of care for citizens, except in cases when emergencies or for health issues implicate several regions, but the strategies to achieve them are decided and implemented at regional level. For the new 'National Plan of Prevention', the CNESPS will be adapting PROFEA training modules to assure that health professionals acquire the skills and competencies necessary for these new tasks. In the future selection of candidates will be possibly carried out by the regions and the number PROFEA trainees could rise to 20 per cohort. The funds for the programme could come directly from the interested regions and not from the national level (Ministry of Health).

\section{Norway}

The Norwegian Field Epidemiology Training Programme (NorFETP) started in 2001 with the objective 'to strengthen Norway's capacity to prevent and control communicable diseases by training highly qualified physicians, veterinarians and public health nurses in surveillance, outbreak investigations, applied research, communication, and support for decision making'. The focus of the programme is infectious disease prevention and control. It has from the start benefited immensely from a close collaboration with EPIET and as such adopted the EPIET associated-programme model.

During the two-year training period, fellows are actively involved in field investigations, surveillance and related research activities, and get acquainted with laboratory methods relevant to epidemiological investigations. If feasible they also take part in the Nordic summer school of infectious disease epidemiology (two weeks), go on a site visit to another European department of infectious disease surveillance, to the ECDC or the World Health Organisation (WHO) for at least one week and attend an international scientific conference. The objectives of the Nor-FETP are the same as those of EPIET plus some additional Nor-FETP objectives, such as: becoming acquainted with the Norwegian Surveillance System for Communicable Diseases, the EpiNorth collaboration [8] and with one ECDC/EU network for surveillance of infectious diseases [9].

The main working language is Norwegian but most reports, presentations and publications are in English, depending on the target audience. The three most recent fellows to join the programme are in parallel involved in training for the medical specialty in public health medicine. Their Nor-FETP training will count towards this specialisation. Normally, one fellowship is awarded per year. Nor-FETP uses the same criteria for selection as EPIET plus: fluency in a Scandinavian language; the intention to work in public health in Norway and international experience, e.g. in research or NGO work.

The Nor-FETP is managed by the Norwegian Institute of Public Health. The daily administration is in the Department of Infectious Disease Epidemiology, where the fellows are trained. To fulfil the training objective of training other professionals, the Nor-FETP programme collaborates with the EpiNorth project, the International School of Public Health in Arkhangelsk, Russia and the Nordic School of Public Health.

Since its inception, four fellows have completed training while three are in the programme now and one has been selected for the upcoming cohort and there was no drop-out. Among these eight, four are physicians, one is a veterinarian with $\mathrm{a} P \mathrm{Ph}$ and three are registered nurses with a master degree in public health when entering the programme.

The main challenge when setting up Nor-FETP was to organise training modules for so few people. The collaboration with EPIET solved this and is crucial for the programme and which is expected to continue in its current form.

\section{Spain}

The Spanish Applied Field Epidemiology Training Programme (PEAC) was launched in 1994 by the Ministry of Health supported by the US CDC, Atlanta [10]. The programme is hosted by the National Centre for Epidemiology in close collaboration with the National School of Public Health, both at the Instituto de Salud Carlos III (ISCIII, National Public Health Institute). The mission of ISCIII is to provide and offer scientific and technical support, as well as high quality research and training, to the national health system and the society. Within this framework, the objective of the PEAC is to strengthen the capacity of response of the national surveillance system to epidemics and other health emergencies.

PEAC starts with a three-month introductory course together with the Spanish Master of Public Health course at the national public health institute. Additional modules include: data management and data analysis, outbreak investigation (general and special aspects), communication, infectious disease epidemiology, environmental epidemiology, occupational epidemiology, analysis of health situation and application of systems dynamics. Participation is obligatory for all modules which are all held in Spanish. The 


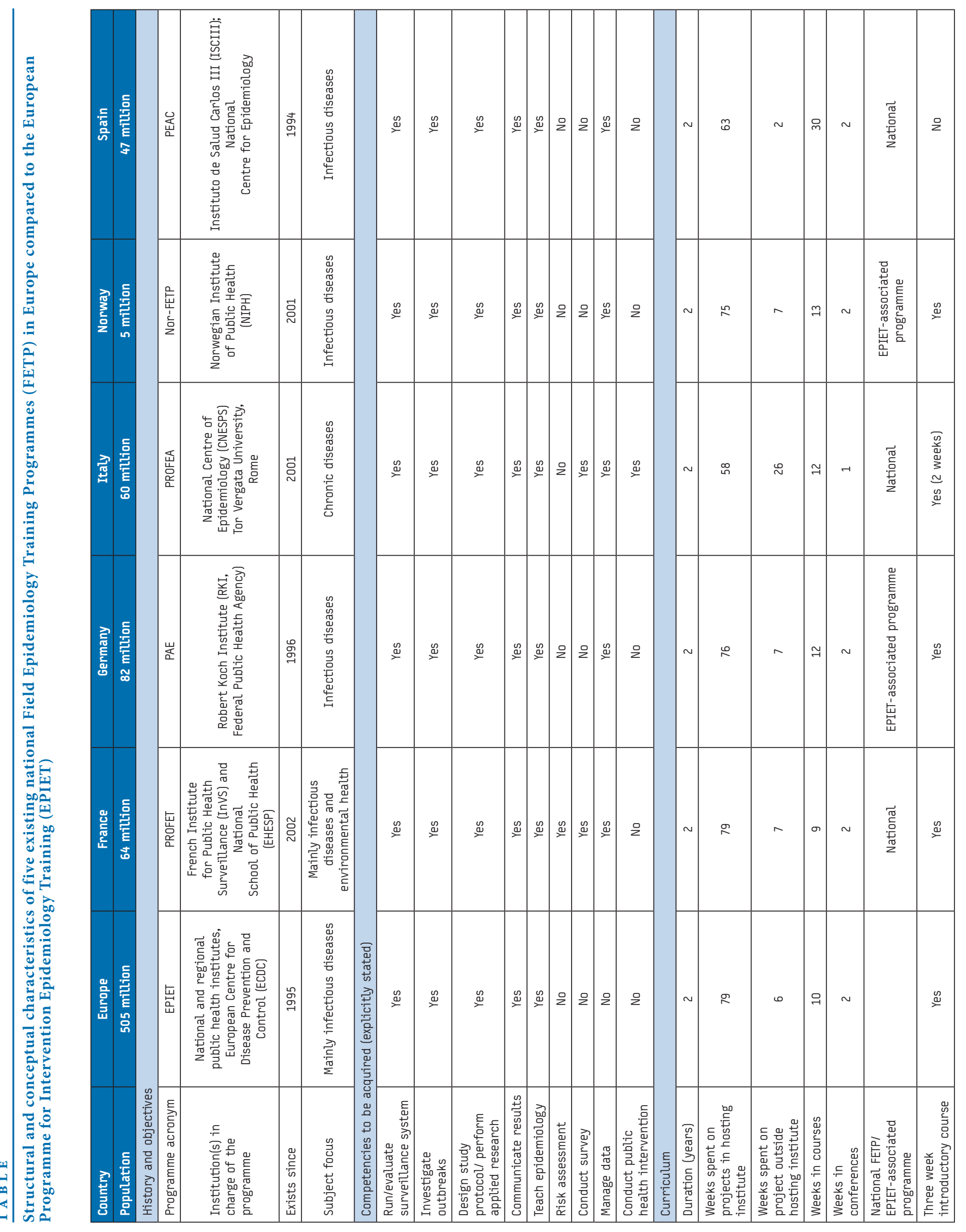




\begin{tabular}{|c|c|c|c|c|c|c|c|c|c|c|c|c|c|c|}
\hline 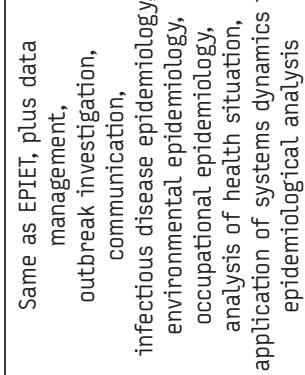 & $\stackrel{0}{\tilde{c}}$ & 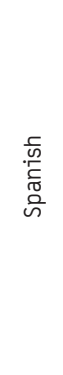 & 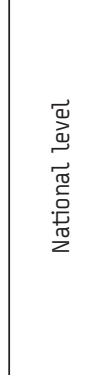 & 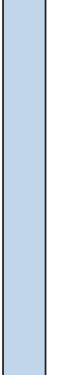 & q & $\stackrel{\mathscr{g}}{=}$ & 2 & 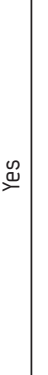 & 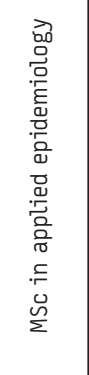 & 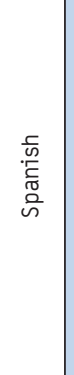 & 崫 & $\stackrel{\varphi}{\dot{m}}$ & 虽 & 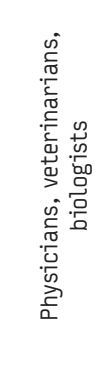 \\
\hline 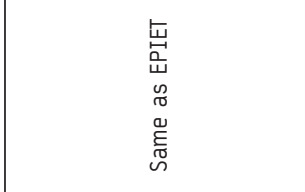 & 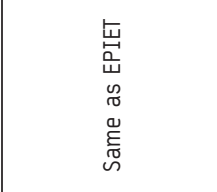 & 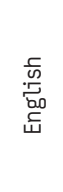 & 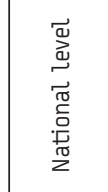 & 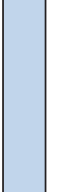 & 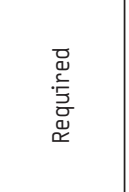 & 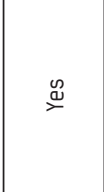 & $\frac{0}{2}$ & $\stackrel{\mathscr{\Xi}}{\approx}$ & 운 & 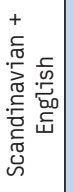 & $\begin{array}{l}\text { 崖 } \\
\stackrel{\sim}{0}\end{array}$ & 0 & $\dashv$ & 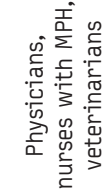 \\
\hline$\frac{\pi}{z}$ & 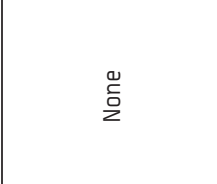 & 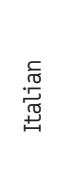 & 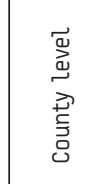 & & 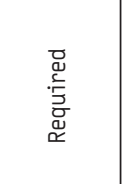 & $\stackrel{\infty}{=}$ & $\frac{1}{2}$ & 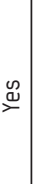 & 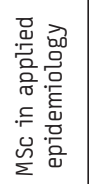 & $\begin{array}{l}\text { 宽 } \\
\text { 覀 }\end{array}$ & 㟶 & $\sim$ & $\underset{\substack{\sim \\
\infty}}{\stackrel{\sim}{n}}$ & $\begin{array}{l}0 \\
0 \\
0 \\
0 \\
\Xi \\
ٌ \\
心\end{array}$ \\
\hline 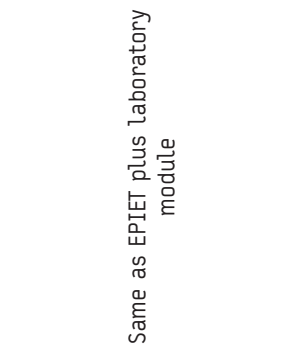 & 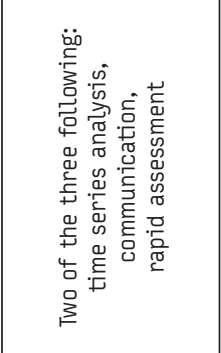 & 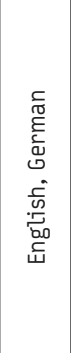 & 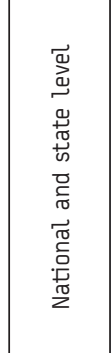 & & $\frac{0}{2}$ & $\stackrel{\mathscr{ٌ}}{=}$ & 2 & $\stackrel{\infty}{\stackrel{\infty}{\Perp} .}$ & 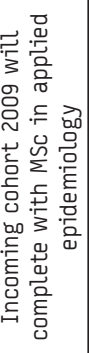 & 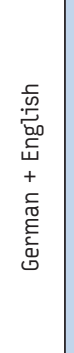 & $\underset{\sim}{\stackrel{\vec{\sim}}{\sim}}$ & 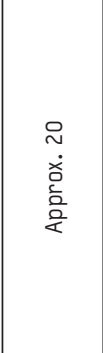 & $\stackrel{\frac{\infty}{\infty}}{\underset{\infty}{\sim}}$ & 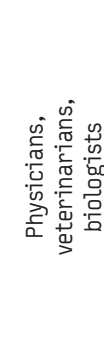 \\
\hline 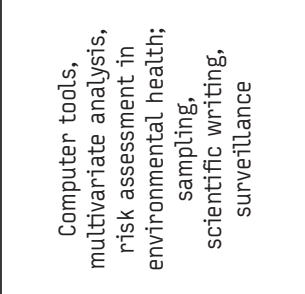 & $\begin{array}{l}\stackrel{0}{\tilde{c}} \\
\text { L }\end{array}$ & $\begin{array}{l}\frac{5}{0} \\
\text { w్ } \\
\underline{w}\end{array}$ & 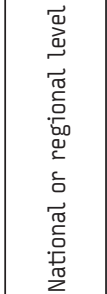 & & 울 & 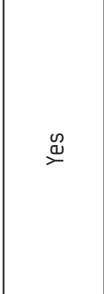 & 2 & 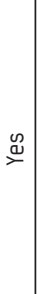 & 운 & $\begin{array}{l}\frac{c}{0} \\
\bar{w} \\
w \\
w\end{array}$ & 岸 & 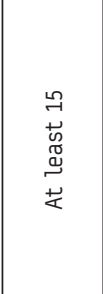 & 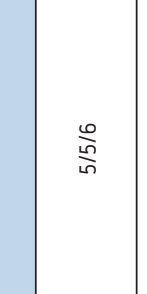 & 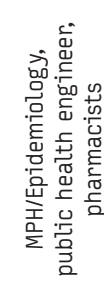 \\
\hline 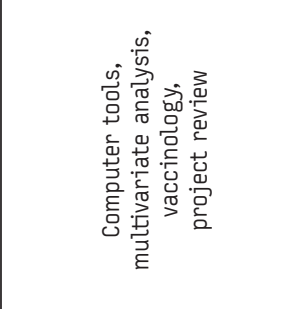 & 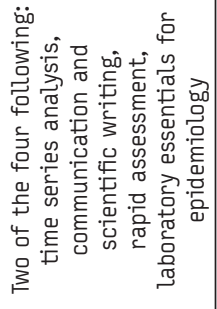 & 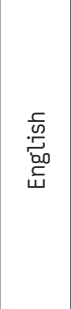 & 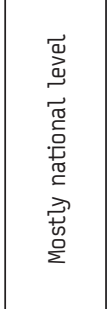 & 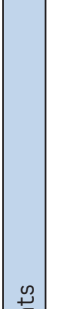 & 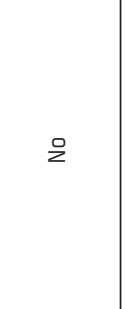 & $\stackrel{\infty}{\stackrel{\infty}{~}}$ & & 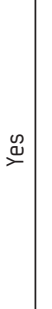 & qo & 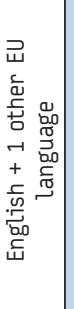 & 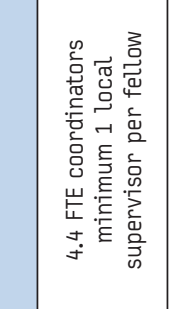 & 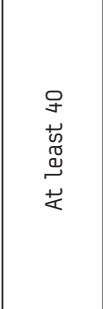 & $\begin{array}{l}\stackrel{9}{9} \\
\stackrel{7}{0}\end{array}$ & 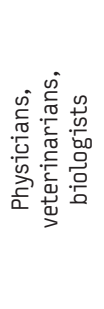 \\
\hline 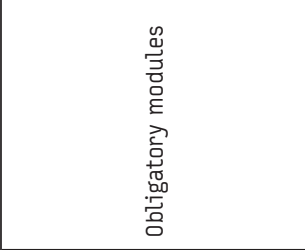 & 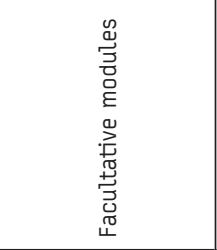 & 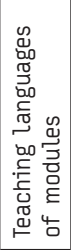 & 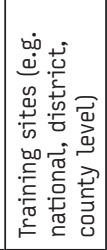 & 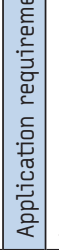 & 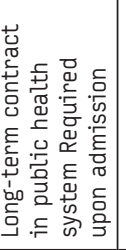 & 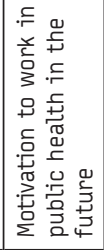 & 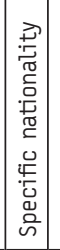 & 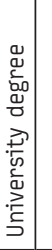 & 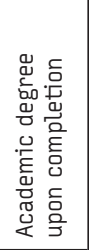 & 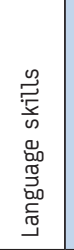 & 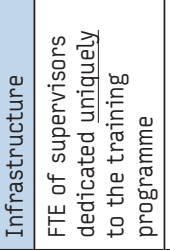 & 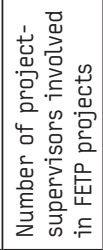 & 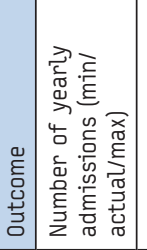 & 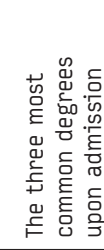 \\
\hline
\end{tabular}




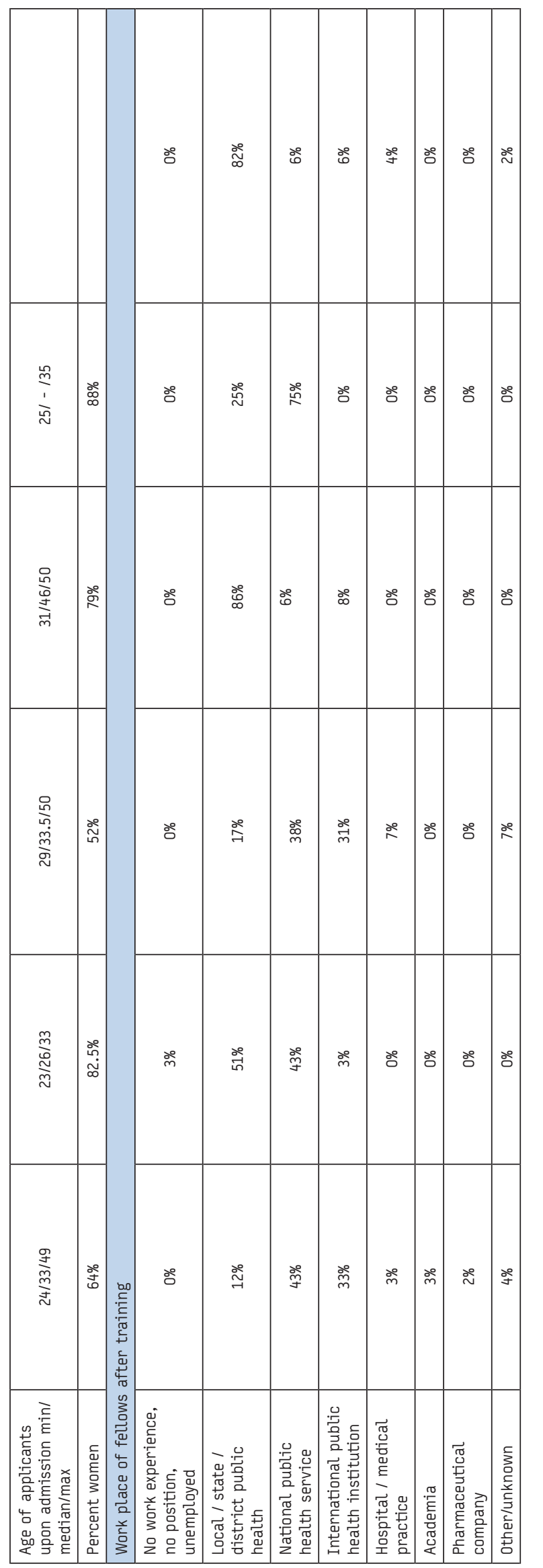

programme mainly focuses on infections diseases. During the two-year programme, trainees have to evaluate or implement a surveillance system, develop an epidemiologic study and conduct an outbreak investigation and study at least one outbreak. At the end of the training, fellows obtain a master degree.

Application requirements for PEAC include a university degree in a health-related field, and professional experience of at least two years in public health. Every year the ISCIII offers at least five fellowships, complemented by at least one additional fellowship from the Spanish International Cooperation Agency for applicants from Latin America or Africa, and one fellowship from the Ministry of Defense for a member of the army. The cohort can also be completed with professionals currently working at the Autonomous Regions' health administrations. The PEAC coordination team consists of one academic director and two full time scientific coordinators. Scientific coordinators follow the development of the trainees' objectives, review all the draft projects and lead some of them. For some specific projects, senior epidemiologists from national and regional level are involved in the supervision and contribute to training modules.

PEAC is currently running cohorts 14 and 15 with seven and nine fellows respectively. Up to now 109 professionals have been trained, 4 to 10 fellows per cohort. Fellows are mainly physicians (78) followed by biologists (9) and veterinarians (9). The Spanish programme is also hosting normally one EPIET fellow per year. The programme has trained 10 professionals from Latin-América (Argentina, Colombia, Cuba, Haití, Nicaragua, Uruguay and Venezuela) and Africa (Mozambique and Cape Verde). Ninety-five percent of the PEAC graduates currently work in epidemiological surveillance, alert and response units or surveillance of noncommunicable diseases. Over half of the PEAC graduates are working in leading positions in epidemiological surveillance in public health administration at local, regional, or central level in Spain and in other countries. Some are collaborating actively in training field epidemiologists in their administrations.

The PEAC was created in an institution belonging to the Ministry of Health, and it was oriented to cover the shortage of professionals trained in applied epidemiology at central and regional levels. The first trainees were professionals from within the public health administration and the curriculum was based on short courses with very specific goals tailored to their specific needs. Meanwhile, applicants have often less work experience in the public health service and use the programme as a way to enter the public health work force. In response to this change PEAC is now including core courses on general public health. In 2009, the programme was moved to the Ministry of Science and Innovation which has improved the facilitation of original research but has diminished collaboration with the autonomous regions and thus lessened the fellows' opportunities to participate in outbreak investigations. The challenge is now to intensify the cooperation with the autonomous regions again.

\section{Conclusion}

Our overview shows that the existing five national FETP in Europe are differently organised in the various countries, and it is not evident whether the methodological differences reflect a difference in training needs or rather are the result of historic opportunities and training traditions in the respective countries. However, we demonstrate that all national programmes fulfil one of their main objectives which is to strengthen the national capacity 
in applied field epidemiology, in such that most people do work in public health in their countries after completion the programme, many of them in leading functions. These findings are in line with those published in the paper by Bosman et al. in the same issue of this journal.

As concerns the particularities of the various programmes, the Italian FETP is very much a close system, while the German PAE seems to have been able to attract young professionals from outside the public health service, with a scientific background to dedicate and strengthen their skills for public health epidemiology. This may of course not be a result of the training programmes themselves but more a result of the overall flexibility of the staffing activities and penetration possibilities in the respective public health service, which in turn may become the most important determinant on how the public health work force in European countries will develop.

Looking back at the situation of FETP in 2001, some impressive improvements are visible. Three more programmes, the Italian, French and Norwegian FETP were created, the German FETP has become stronger and new EPIET-associated programmes were installed. In the editorial to the above mentioned overview in Eurosurveillance in 2001, Reingold has predicted Europe to face a bright future with respect to FETP [1]. Given the time that has elapsed since that statement, the indisputable progress with respect to the establishment of national FETP or EPIET-associated programmes is admittedly slow. Member States should be aware of how much support EPIET can offer for the establishment of national FETP or EPIET-associated programmes. However, they also need to be ready to provide the necessary resources, the administrative environment and long-term dedication to make field epidemiology training work.

\section{References}

1. Reingold AL. Field epidemiology training in Europe faces a bright future . Euro Surveill. 2001;6(3):pii=215. Available from: http://www.eurosurveillance. org/ViewArticle. aspx?ArticleId $=215$

2. Ostroff SM. The Epidemic Intelligence Service in the United States . Euro Surveill. 2001;6(3):pij=216. Available from: http://www.eurosurveillance.org/ ViewArticle.aspx?ArticleId=216

3. Malfait P, Helynck B. Seventeen years of intervention epidemiology training at Veyrier-du-Lac, 1984-2000. Euro Surveill. 2001;6(3):pii=217. Available from: http://www.eurosurveillance.org/ViewArticle.aspx?ArticleId=217

4. Helynck B. A national training programme in field epidemiology launched in France. Euro Surveill. 2002;7(5):pii=370. Available from: http://www. eurosurveillance.org/ViewArticle.aspx?ArticleId $=370$

5. Petersen LR, Breuer T, Hamouda 0, Ammon A. The Field Epidemiology Training Program (FETP) in Germany. Euro Surveill. 2001;6(3):pii=219. Available from: http://www.eurosurveillance.org/ViewArticle. aspx?ArticleId=219

6. Bremer V, Bosman A, Coulombier D. New perspectives after the transition of EPIET to ECDC - the future of the programme. Euro Surveill. 2009;14(42):pii=19374. Available from: http://www.eurosurveillance.org/ ViewArticle.aspx?ArticleId $=19374$

7. Bremer V, Alpers K, Krause G. Intervention epidemiology training programs in Germany and Europe. Bundesgesundheitsblatt - Gesundheitsforschung Gesundheitsschutz 2009 Feb;52(2):203-7.

8. EpiNorth [Internet]. Oslo. [cited 29 October 2009]. Available from: www. epinorth,org

9. Decision no 2119/98/EC of the European Parliament and of the Council of 24 September 1998 setting up a network for the epidemiological surveillance and control of communicable diseases in the Community. Official Journal of the European Communities 3. 10. $98 \mathrm{~L} 268$.

10. Martinez Navarro JF, Herrera D, Candi Sanchez Barco. Applied field epidemiology programme in Spain. Eurosurveillance 2001 Mar;6(3):46-7.

11. Bosman A, Schimmer B, Coulombier D. Contribution of EPIET to public health workforce in the EU, 1995-2008. Euro Surveill. 2009;14(43):pij=19381. Available from: http://www.eurosurveillance.org/ViewArticle.aspx?ArticleId=19381 